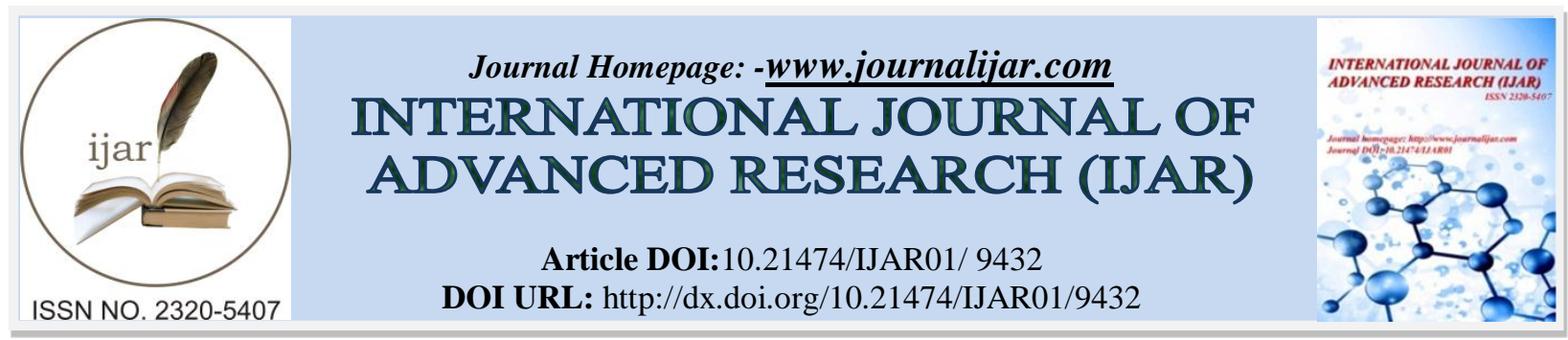

RESEARCH ARTICLE

\title{
EFFECTIVENESS OF BACK SCHOOL EXERCISE VERSUS YOGASANA AMONG SCHOOL TEACHERS WITH CHRONIC LOW BACK PAIN: A RANDOMIZED CONTROLLED TRIAL.
}

Swati S. Dhrangu ${ }^{1}$ and Amit Sharma ${ }^{2}$.

1. MPT in Musculoskeletal condition and sports science, Assistant professor, School of Physiotherapy, R.K. University, Rajkot, Gujarat, India.

2. MPT in Musculoskeletal condition and sports science, Associate professor, School of Physiotherapy, R.K. University, Rajkot, Gujarat, India.

\section{Manuscript Info}

.........................

Manuscript History

Received: 24 May 2019

Final Accepted: 26 June 2019

Published: July 2019

Key words:-

WMSD, NPRS, RMDQ, ROM, LBP, Back

School Exercise, Yogasana.

\section{Abstract}

Background: The back school method was developed in 1969 in Sweden by Mariane Zachrisson Forsell, with the goal of treating the patient's current periods and avoiding recurrent periods of LBP. The purpose of the present study was that there are many studies occurs in back pain and also back school exercise, but back school versus yogasana is not compare till now. So there is a need to compare back school exercise versus yogasana for a patient with chronic low back pain.

Aims: To find out the effectiveness of active mean of Intervention for the low back pain in school teachers of rural area to improve pain intensity, quality of life and range of motion.

Methodology: 45 school teachers were selected based on inclusion and exclusion criteria. All the subjects were divided into the three groups of 15 each out of which group A was given back school exercise, group B was given yogasana and group $\mathrm{C}$ was control group for One day/ week for 4 weeks. Outcome measures were taken NPRS, RMDQ and ROM. The data were analyzed by paired $t$ test and one way anova test.

Results and Discussion: The Test Result Shown Improvement in The Group A And Group B Compared To The Control Group. But there was more significant improvement shown in group A than the yogasana. On The Based Of That Shows Decrease The Intensity Of Pain And Disability In Group A Than The Other Groups.

Conclusions: The study concluded that Back school exercises and yogasana both the treatment are effective in reducing low back pain intensity in the school teachers compared to the control group. But back school exercises showed slightly more improvement in the health status of the subjects than the yogasana group in the four weeks of the study

Copy Right, IJAR, 2019,. All rights reserved.

\section{Introduction:-}

"The Only Disability in Life Is a Bad Attitude" message by Scott Hamilton. Musculoskeletal condition is very communal seen in a work-related conditions issue in equally urban and unindustrialized mother lands. Through

Corresponding Author:-Swati S. Dhrangu.

Address:-MPT in Musculoskeletal condition and sports science, Assistant professor, School of Physiotherapy, R.K. University, Rajkot, Gujarat, India. 
public manufacture extremely computerized on the job of the musculoskeletal condition, which are major health issues by authorities. In several developing nations, occupational musculoskeletal disorders are in second highest work-related illness then the work-related mental illness. A major study has also newly proposed that school teachers are at very high risk of musculoskeletal conditions, by incidence amounts stated are among $12 \%$ and $84 \%$. $^{1-}$

${ }^{11}$ In general, school teachers have been proved that further working groups have a high incidence of musculoskeletal conditions with incidence amounts of between $40 \%$ to $95 \%$.during this work, teachers may be reported as a physical fitness issue. Standing for long periods of time that is lead to lower back pain and also a leg pain. ${ }^{12}$

Low back pain is commonly accepted as a very fitness and socio-economic issues which waves a huge number of people in industrial nations. Now a day's condition is very poor in rising nations by the suboptimal employed situation in several activities and an acute absence of consciousness of ergonomics problems, learning and teaching programmes. Equally circulated among gender $45 \%$ of men and $58 \%$ of women who are suffering from this. In that $75 \%$ are suffering from the LBP condition. ${ }^{13-15}$

A recent structure of medicine yoga also in advance popular in the management of the chronic condition. The list of the back asana are Garudasana, Bhujangasana, and Ustrasana, Dhanurasana, Urdhva Dhanurasana and Salbhasana.Yoga had been proved to manage LBP and mental glitches also. ${ }^{16}$

Many people reduce their pain of LBP with the help of yoga. Yoga created over 2000 years ago in India as a system of bodily, ethical and non-physical practices. Developed in the Scandinavian country by Zachrisson Forsell since 1969 , the so-called back school programme is very used in the world to treat the LBP. In the back school programme it includes educational and skill acquisition program supervised by teachers and motor science experts, including (i) informing patient about spinal anatomy and biomechanics, (ii) correct use of spine, even with respect to all daily activities,(iii) exercise programs for spine function reeducation and pain reduction. ${ }^{17-18}$

The back school method was developed in 1969 in Sweden by Mariane zachrisson Forsell, with the goal of treating the patient's current periods and avoiding recurrent periods of LBP. The program is composed of 4 sessions almost 45 minutes in every session there is theoretical work also include exercise that purpose is to improve flexibility and elasticity and power. ${ }^{19}$

The purpose of the present study was that school teachers are having to prolong standing job due to that they have more chances of chronic low back pain. In the present study, we want to check whether back school exercise and yogasana were reduced chronic low back pain or not. There are many studies occurs in back pain and also back school exercise, but back school versus yogasana is not compared till now. So there is a need to compare back school exercise versus yogasana for a patient with chronic low back pain.

\section{Aim}

To find out the effectiveness of active mean of Intervention for the low back pain in school teachers of rural area to improve pain intensity, quality of life and range of motion.

\section{Method:-}

1. Subject was called as volunteers following to screening with inclusive/exclusive criteria for the study, after taking ethical, informed written consent from subjects study was executed. Before starting the treatment, the patient should be in a comfortable position. Take the NPRS of the subject. Then take the Roland-Morris Disability Questionnaire [RMDQ], and then lumbar spine range of motion has been assessed. Volunteers were be divided into three groups one by one.

2. The first group in the first week of treatment give the presentation of the method, including history and general information about the back school method. Moreover, in the second week gave the Guidance on position when seated or standing Instruction on breathing exercises, kinaesthetic training, stretching of the lower back, quadriceps, and hamstring muscles. In the third week only Observation of the exercises that were performed at home. In the fourth week Practical application of all of the exercises and learned techniques.

3. The second group, we were given the yoga asana and teach them how to do at home.

4. The third group was a control group.

5. This treatment was for four weeks session. After the treatment we were rechecking of outcome measure after four weeks. 


\section{Basic Demographics:}

Name, age, gender, occupation, address.

\section{Basic Anthropometry:}

1. Height was measured by wall Stadiometer

2. Weight measured by the digital bathroom scale

3. BMI calculated by the formula weight $(\mathrm{kgs}) /$ height $^{2}$ (meters) ${ }^{2}$.

\section{Result:-}

1. Forty-five participants were given the one month of the treatment. Pre- Post data were analysed using statistical software SPSS version 21. Microsoft Excel and the word were used to generate graphs and tables.

2. Group A - back school exercise

3. Group B - yogasana

4. Group C - control group

\section{Statistical test:}

1. Intragroup analysis was assessed using Paired t test and intergroup analysis was done using One Way Anova Test.

2. Intergroup comparison of pre and post score was done by using Post Hoc Bonferroni test.

3. The level of significance was $<0.05$.

Demographic Distribution of the School Teachers with chronic low back pain.

\begin{tabular}{|c|c|c|c|c|}
\hline \multicolumn{2}{|c|}{ DEMOGRAPHIC DATA } & GROUP A & GROUP B & GROUP C \\
\hline \multirow{2}{*}{ AGE } & MEAN & 37.33 & 35 & 35.93 \\
\cline { 2 - 5 } & SD & 3.109 & 4.721 & 4.773 \\
\hline \multirow{2}{*}{ BMI } & MEAN & 24.13 & 25.21 & 25.74 \\
\cline { 2 - 5 } & SD & 3.175 & 3.239 & 3.408 \\
\hline
\end{tabular}

Intra Group Comparison of Numerical Pain Rating Scale of Group A, B, and C with Paired T-Test.

\begin{tabular}{|c|c|c|c|c|}
\hline $\begin{array}{c}\text { NUMERICAL PAIN } \\
\text { RATING SCALE }\end{array}$ & $\begin{array}{c}\text { PRE } \\
\text { MEAN } \pm \text { SD }\end{array}$ & $\begin{array}{c}\text { POST } \\
\text { MEAN } \pm \text { SD }\end{array}$ & $\begin{array}{c}\text { T } \\
\text { VALUE }\end{array}$ & $\begin{array}{c}\text { P } \\
\text { VALUE }\end{array}$ \\
\hline GROUP A & $7.47 \pm$ & $2.73 \pm$ & 16.669 & $\mathbf{. 0 0 0}$ \\
& .915 & 1.033 & & $\mathbf{. 0 0 0}$ \\
\hline GROUP B & $6.80 \pm$ & $4.67 \pm$ & 16.00 & \\
& 1.859 & 1.718 & & 1.000 \\
\hline GROUP C & $5.87 \pm$ & $5.87 \pm$ & .000 & \\
\hline
\end{tabular}

Intra Group Comparison of Roland Morris Disability Questionnaire of Group A, B, and C with Paired TTest.

\begin{tabular}{|c|c|c|c|c|}
\hline $\begin{array}{c}\text { ROLAND MORRIS } \\
\text { DISABILITY } \\
\text { QUESTIONNAIRE }\end{array}$ & $\begin{array}{c}\text { PRE } \\
\text { MEAN } \pm \text { SD }\end{array}$ & $\begin{array}{c}\text { POST } \\
\text { MEAN } \pm \text { SD }\end{array}$ & $\begin{array}{c}\text { T } \\
\text { VALUE }\end{array}$ & $\begin{array}{c}\text { P } \\
\text { VALUE }\end{array}$ \\
\hline GROUP A & $16.47 \pm$ & $7.93 \pm$ & 7.341 & $\mathbf{. 0 0 0}$ \\
& 3.482 & 2.840 & & \\
\hline
\end{tabular}




\begin{tabular}{|c|c|c|c|c|}
\hline GROUP B & $15.20 \pm$ & $11.33 \pm$ & 12.614 & $\mathbf{. 0 0 0}$ \\
& 3.448 & 3.309 & & \\
\hline \multirow{2}{*}{ GROUP C } & $14.07 \pm$ & $13.93 \pm$ & 1.000 & .334 \\
& 4.200 & 4.267 & & \\
\hline
\end{tabular}

Intra group Comparison of Range of Motion Of Group A, B, and C with Paired t-Test.

\begin{tabular}{|c|c|c|c|c|}
\hline $\begin{array}{c}\text { RANGE OF } \\
\text { MOTION }\end{array}$ & $\begin{array}{c}\text { PRE } \\
\text { MEAN } \pm \text { SD }\end{array}$ & $\begin{array}{c}\text { POST } \\
\text { MEAN } \pm \text { SD }\end{array}$ & $\begin{array}{c}\text { T } \\
\text { VALUE }\end{array}$ & $\begin{array}{c}\text { P } \\
\text { VALUE }\end{array}$ \\
\hline GROUP A & $\begin{array}{c}4.33 \pm \\
1.047\end{array}$ & $\begin{array}{c}7.27 \pm \\
1.387\end{array}$ & -7.192 & .000 \\
\hline GROUP B & $3.80 \pm$ & $5.33 \pm$ & -11.500 & .000 \\
& 1.014 & 1.047 & & .334 \\
\hline \multirow{2}{*}{ GROUP C } & $4.07 \pm$ & $4.00 \pm$ & 1.000 & \\
\hline
\end{tabular}

Intergroup comparison of pre and post Numerical Pain Rating Scale with One Way Anova Test.

\begin{tabular}{|c|c|c|c|c|c|}
\hline \multicolumn{2}{|c|}{$\begin{array}{l}\text { NUMERICAL PAIN } \\
\text { RATING SCALE }\end{array}$} & $\mathbf{N}$ & MEAN & STD. DEVIATION & P-VALUE \\
\hline \multirow[t]{4}{*}{ Pre } & GA & 15 & 7.47 & .915 & \multirow{3}{*}{.028} \\
\hline & GB & 15 & 6.80 & 1.859 & \\
\hline & GC & 15 & 5.87 & 1.767 & \\
\hline & Total & 45 & 6.71 & 1.674 & \\
\hline \multirow[t]{4}{*}{ Post } & GA & 15 & 2.73 & 1.033 & \multirow{3}{*}{$.000(S)$} \\
\hline & GB & 15 & 4.67 & 1.718 & \\
\hline & GC & 15 & 5.87 & 1.807 & \\
\hline & Total & 45 & 4.42 & 2.006 & \\
\hline
\end{tabular}

Intergroup Comparison of Post Numerical Pain Rating Scale with Post Hoc Test (Bonferroni Test)

\begin{tabular}{|c|c|c|c|c|}
\hline $\begin{array}{ll}\text { NUMERICAL } & \text { PAIN } \\
\text { RATING SCALE } & \end{array}$ & & & $\begin{array}{c}\text { MEAN } \\
\text { DIFFERENCE }\end{array}$ & P-VALUE \\
\hline \multirow{6}{*}{ POST } & \multirow[t]{2}{*}{ GA } & GB & -1.933 & $.004(S)$ \\
\hline & & GC & -3.133 & $.000(S)$ \\
\hline & \multirow[t]{2}{*}{ GB } & GA & 1.933 & $.004(S)$ \\
\hline & & GC & -1.200 & .123 \\
\hline & \multirow[t]{2}{*}{ GC } & GA & 3.133 & $.000(S)$ \\
\hline & & GB & 1.200 & .123 \\
\hline
\end{tabular}


Intergroup comparison Of Pre and Post Roland Morris Disability Questionnaire with One Way Anova Test.

\begin{tabular}{|c|c|c|c|c|c|}
\hline \multicolumn{2}{|c|}{$\begin{array}{l}\text { ROLAND MORRIS } \\
\text { DISABILITY } \\
\text { QUESTIONARRIE }\end{array}$} & $\mathbf{N}$ & MEAN & $\begin{array}{l}\text { STD. } \\
\text { DEVIATION }\end{array}$ & P-VALUE \\
\hline Pre & GA & 15 & 16.47 & 3.482 & \multirow{3}{*}{.223} \\
\hline & GB & 15 & 15.20 & 3.448 & \\
\hline & GC & 15 & 14.07 & 4.200 & \\
\hline & Total & 45 & 15.24 & 3.773 & \\
\hline \multirow[t]{4}{*}{ Post } & GA & 15 & 7.93 & 2.840 & \multirow{3}{*}{$.000(S)$} \\
\hline & GB & 15 & 11.33 & 3.309 & \\
\hline & GC & 15 & 13.93 & 4.267 & \\
\hline & Total & 45 & 11.07 & 4.245 & \\
\hline
\end{tabular}

Inter Group comparison of Post Roland Morris Disability Questionnaire with Post Hoc Test (Bonferroni Test)

\begin{tabular}{|c|c|c|c|c|}
\hline $\begin{array}{c}\text { ROLAND MORRIS } \\
\text { DISABILITY } \\
\text { QUESTIONARRIE }\end{array}$ & & $\begin{array}{c}\text { MEAN } \\
\text { DIFFERENCE }\end{array}$ & P-VALUE \\
\hline \multirow{3}{*}{ POST } & $\mathbf{G A}$ & GB & -3.400 & .034 \\
\cline { 3 - 5 } & $\mathbf{G B}$ & GC & -6.000 & .000 \\
\cline { 2 - 5 } & & GA & 3.400 & .034 \\
\cline { 2 - 5 } & \multirow{2}{*}{ GC } & GC & -2.600 & .149 \\
\cline { 2 - 5 } & & GB & 6.000 & .000 \\
\hline
\end{tabular}

Inter Group comparison Of Pre and Post Range of Motion With One Way Anova Test.

\begin{tabular}{|c|c|c|c|c|c|}
\hline \multirow{3}{*}{ RANGE OF MOTION } & N & Mean & Std. Deviation & \multirow{2}{*}{ P VALUE } \\
\hline \multirow{3}{*}{ Pre } & GA & 15 & 4.33 & 1.047 & \multirow{2}{*}{.495} \\
\cline { 2 - 5 } & GB & 15 & 3.80 & 1.014 & \\
\cline { 2 - 5 } & GC & 15 & 4.07 & 1.534 & \\
\cline { 2 - 5 } & Total & 45 & 4.07 & 1.214 & \multirow{2}{*}{$\mathbf{. 0 0 0 ( S )}$} \\
\cline { 2 - 5 } Post & GA & 15 & 7.27 & 1.387 & \\
\cline { 2 - 5 } & GB & 15 & 5.33 & 1.047 & \\
\cline { 2 - 5 } & GC & 15 & 4.00 & 1.902 & \\
\cline { 2 - 5 } & Total & 45 & 5.53 & & \\
\hline
\end{tabular}

Inter Group comparison of Post Range of Motion With Post Hoc Test (Bonferroni Test)

\begin{tabular}{|c|c|c|c|c|}
\hline \multirow{3}{*}{ RANGE OF MOTION } & & & $\begin{array}{c}\text { MEAN } \\
\text { DIFFERENCE }\end{array}$ & P-VALUE \\
\hline \multirow{3}{*}{ POST } & \multirow{3}{*}{ GA } & GB & 1.933 & .001 \\
\cline { 3 - 5 } & & GC & 3.267 & .000 \\
\cline { 2 - 5 } & \multirow{2}{*}{ GB } & GA & -1.933 & .001 \\
\cline { 2 - 5 } & & GC & 1.333 & .032 \\
\cline { 2 - 5 } & \multirow{2}{*}{ GC } & GA & -3.267 & .000 \\
\cline { 3 - 5 } & & GB & -1.333 & .032 \\
\hline
\end{tabular}

\section{Discussion:-}

The purpose of the study was to find out of the effectiveness of active mean of Intervention for the low back pain in school teachers of rural area to improve in pain intensity, quality of life and range of motion. 
The present study showed that the intragroup comparison of all the outcome was done using the statistical test paired $\mathrm{t}$-test, which has shown statistical significance difference in both the groups $(\mathrm{p}<0.05)$. However, the control group did not show any improvement after four weeks of study ( $p>00.05$ )

Intergroup comparison was done using one-way ANOVA test (post HOC test) that shows there is no significant difference between back school exercise and yogasana group but back school and control group shows there was a significant difference between both the groups.

So, here the present study showed that group A is more effective compared to the other groups. On the based of that shows decrease the intensity of pain and disability in group A than the other groups.

So, here the null hypothesis was rejected and the experimental hypothesis was accepted.

\section{Limitations of the study}

1. Small sample size.

2. It was not possible to monitor the home exercise program.

\section{Future recommendations of the study}

1. Long duration study should be conducted with the same regime like by increasing the number of weeks. E.g.: six weeks, eight weeks, etc.

2. Studies can be done in different occupations.

\section{Conclusion:-}

1. The study concluded that Back school exercises and yogasana both the treatment are effective in reducing low back pain intensity in the school teachers compared to the control group.

2. However, back school exercises showed slightly more improvement in the health status of the subjects than the yogasana group in the four week of the study.

\section{Funding statement:}

Self

\section{Conflict of interest:}

There was no personal or institutional conflict of interest for this study.

\section{Acknowledgement:}

I would like to thanks Dr. Ankita Chauhan for helping me in this study. And also my parents for their support.

\section{Reference:-}

1. Erick PN, Smith DR. A systematic review of musculoskeletal disorders among school teachers. BMC Musculoskelet Disord. 2011; 12:260. doi: 10.1186/1471-2474-12-260.

2. Brannmark M, Hakansson M. Lean production and work-related musculoskeletal disorders: overviews of international and Swedish studies. Work. 2012; 41:2321-2328.

3. Boschman JS, van der Molen HF, Sluiter JK, Frings-Dresen MHW. Musculoskeletal disorders among construction workers: a one-year follow-up study. BMC Musculoskelet Disord. 2012; 13:9. doi: 10.1186/14712474-13-196.

4. Sharan D, Parijat P, Sasidharan AP, Ranganathan R, Mohandoss M, Jose J. Workstyle Risk Factors for Work Related Musculoskeletal Symptoms Among Computer Professionals in India. J Occup Rehabil. 2011; 21(4):520-525. doi: 10.1007/s10926-011-9294-4.

5. Cardoso JP, Araujo TM, Carvalho FM, Oliveira NF, Reis EJ. Psychosocial work related factors and musculoskeletal pain among schoolteachers. Cad Saude Publica. 2011; 27(8):1498-1506. doi: 10.1590/S0102311 X2011000800005.

6. Douphrate DI, Fethke NB, Nonnenmann MW, Rosecrance JC, Reynolds SJ. Full shift arm inclinometry among dairy parlor workers: A feasibility study in a challenging work environment. Appl Ergon. 2012; 43(3):604-613. doi: 10.1016/j.apergo.2011.09.007. 
7. Passier L, McPhail S. Work related musculoskeletal disorders amongst therapists in physically demanding roles: qualitative analysis of risk factors and strategies for prevention. BMC Musculoskelet Disord. 2011; 12:9. doi: 10.1186/1471-2474-12-24.

8. Korkmaz NC, Cavlak U, Telci EA. Musculoskeletal pain, associated risk factors and coping strategies in school teachers. Sci Res Essays. 2011; 6(3):649-657.

9. Erick PN, Smith DR: A systematic review of musculoskeletal disorders among school teachers. BMC Musculoskelet Disord. 2011, 12 (1): 260-10.1186/1471-2474-12-260.

10. Kovač M, Leskošek B, Hadžić V, Jurak G: Occupational health problems among Slovenian physical education teachers. Kinesiology. 2013, 45 (1): 92-100.

11. Pihl E, Matsin T, Jurimae T: Physical activity, musculoskeletal disorders and cardiovascular risk factors in male physical education teachers. J Sports Med Phys Fitness. 2002, 42 (4): 466-471.

12. Elaine Y. L. Chong \& Alan H. S. Chan Subjective Health Complaints of Teachers from Primary and Secondary Schools in Hong Kong. JOSE 2010, Vol. 16, No. 1

13. Smith DR, Leggat PA, Speare R: Musculoskeletal disorders and psychosocial risk factors among veterinarians in Queensland. Australia Aust Vet J. 2009, 87 (7): 260-265. 10.1111/j.1751-0813.2009.00435.x.

14. Bongers PM, Kremer AM, Laak JT: Are psychosocial factors, risk factors for symptoms and signs of the shoulder, elbow, or hand/wrist? A review of the epidemiological literature. Am J Ind Med. 2002, 41 (5): 315342. 10.1002/ajim.10050.

15. Freburger, J.k., Holmes, G.M., agans, R.P., Jackman, A.M. the rising prevelance of chronic low back pain: international archieves of medicine, (2009).169:251-258.

16. Alternative Therapeuties, Swati Bhagat, First Edition, 2004.

17. Forssell MZ. The Swedish Back School. Physiotherapy. 1980 Apr; 66(4):112-114.

18. Van Der Hulst M, Vollenbroek-Hutten MMR, Ijzerman MJ. A systematic review of sociodemographic, physical, and psychological predictors of multidisciplinary rehabilitation-or, back school treatment outcome in patients with chronic low back pain. Spine (Phila Pa 1976). 2005 Apr 1; 30(7):813-825.

19. Martijn H, Van tukder MW, Rosmin E, et al. back school for nonspecific low back pain. Cochrane Database Syst Rev. 2012 ; (1):CD006555. 